\title{
Análise experimental comparativa entre concreto reciclado com agregado graúdo oriundo da reciclagem de resíduo de construção e demolição
}

Comparative experimental analysis between recycled concrete with coarse aggregate from the recycling of construction and demolition waste

Análisis experimental comparativo entre hormigón reciclado com árido grueso procedente del reciclaje de resíduos de construcción y demolición

\author{
Amanda Celestino Ponte \\ ORCID: https://orcid.org/0000-0002-1364-7335 \\ Centro Universitário UNINTA, Brasil \\ E-mail: amandarayzane@ hotmail.com \\ Mariana Medeiros Ximenes \\ ORCID: https://orcid.org/0000-0002-9638-0735 \\ Centro Universitário UNINTA, Brasil \\ E-mail: xm.mariana@gmail.com \\ Sedna Karla Uchôa Fernandes \\ ORCID: https://orcid.org/0000-0001-7477-5712 \\ Centro Universitário UNINTA, Brasil \\ E-mail: sedna.uchoa@gmail.com
}

\begin{abstract}
Resumo
O setor da construção civil está cada vez mais em expansão em decorrência do crescimento demográfico; consequentemente, maior demanda por construção de habitações. Porém, têm-se percebido um aumento alarmante no volume de geração dos resíduos sólidos oriundos de construção e demolição (RCD). Diante disso, esse trabalho tem como objetivo principal utilizar resíduos gerados por perdas físicas em canteiros de obras para substituição parcial e total do agregado graúdo dos concretos convencionais e analisar sua eficiência para fins estruturais. Para isso foram realizados ensaios experimentais com substituição de agregado graúdo convencional por agregado constituído de resíduos de construção e demolição nos teores de $50 \%$ e $100 \%$. Os resultados obtidos foram comparados com o do concreto convencional. A reutilização de RCD na fabricação dos concretos convencionais poderá trazer um manejo sustentável nas construções, visto que sua utilização pode gerar redução na exploração de recursos naturais, diminuição no volume de resíduo depositado no meio ambiente e redução na emissão de CO2, gerada pelas operações de transporte desse material até a destinação final. Portanto, buscou-se reunir dados/pesquisas com o propósito de apresentar como a viabilidade da confecção de concreto reciclado oriundo de resíduo de construção e demolição auxilia na busca por alternativas sustentáveis para deposição desses resíduos. Com os resultados obtidos foi possível observar que os concretos recicláveis apresentaram valores satisfatórios para seu uso na construção civil, desde que seja feito todo controle tecnológico para sua produção e execução, podendo ser utilizado para fins estruturais.
\end{abstract}

Palavras-chave: Resíduos sólidos; Construção; Sustentabilidade.

\begin{abstract}
The civil construction sector is increasingly expanding due to demographic growth; consequently, greater demand for housing construction. However, there has been an alarming increase in the volume of generation of solid waste from construction and demolition (RCD). Therefore, this work has as main objective to use residues generated by physical losses in construction sites for partial and total replacement of the coarse aggregate of conventional concretes and to analyze its efficiency for structural purposes. For this purpose, experimental tests were carried out with the replacement of conventional coarse aggregate for aggregate consisting of construction and demolition waste in the contents of $50 \%$ and $100 \%$. The results obtained were compared with that of conventional concrete. The reuse of RCD in the manufacture of conventional concretes may bring sustainable management to buildings, since their use can generate a reduction in the exploitation of natural resources, a decrease in the volume of waste deposited in the environment and a reduction in the $\mathrm{CO} 2$ emission, generated by the operations of transport of this material to its destination. Therefore, we sought to gather data / research to present how the feasibility of making recycled concrete from construction and demolition waste helps in the search for sustainable alternatives for the deposition of this waste. With the results obtained it was possible to observe that the recyclable concretes presented satisfactory values for their use in civil construction if all technological control is carried out for their production and execution and can be used for structural purposes.
\end{abstract}


Keywords: Solid wast; Construction; Sustainable.

\section{Resumen}

El sector de la construcción civil se está expandiendo cada vez más debido al crecimiento demográfico; en consecuencia, mayor demanda de construcción de viviendas. Sin embargo, ha habido un aumento alarmante en el volumen de generación de residuos sólidos de construcción y demolición (RCD). Por tanto, este trabajo tiene como principal objetivo utilizar los residuos generados por las pérdidas físicas en las obras para la sustitución parcial y total del agregado grueso de los hormigones convencionales y analizar su eficiencia para fines estructurales. Para ello, se realizaron ensayos experimentales con la sustitución de árido grueso convencional por árido constituido por residuos de construcción y demolición en contenidos de 50\% y 100\%. Los resultados obtenidos se compararon con los del hormigón convencional. La reutilización de RCD en la fabricación de hormigones convencionales puede aportar una gestión sostenible a los edificios, ya que su uso puede generar una reducción en la explotación de los recursos naturales, una disminución del volumen de residuos depositados en el medio ambiente y una reducción de la emisión de $\mathrm{CO}$, generado por las operaciones de transporte de este material hasta su destino final. Por lo tanto, buscamos recopilar datos / investigaciones para presentar cómo la viabilidad de hacer concreto reciclado a partir de residuos de construcción y demolición ayuda en la búsqueda de alternativas sostenibles para la deposición de estos residuos. Con los resultados obtenidos se pudo observar que los hormigones reciclables presentaron valores satisfactorios para su uso en construcción civil, siempre que se lleve a cabo todo el control tecnológico para su producción y ejecución, pudiendo ser utilizados con fines estructurales.

Palabras clave: Residuos sólidos; Constructión; Sostenible.

\section{Introdução}

Para Angulo (2000), todo e qualquer resíduo proveniente das atividades de construção é considerado RCD. De acordo com Pinto (1999), nas cidades brasileiras o RCD representa de 41 à 70\% da massa total de resíduos sólidos urbanos (RSU), consequentemente, esses rejeitos geram impactos negativos ao meio ambiente.

O RCD tem, no mínimo, duas fontes de geração típicas: construção e demolição. No Brasil, estima-se que mais de $50 \%$ do RCD é originado das construções provenientes de perdas físicas de alguns materiais, geradas a partir do processo de construção e demolição (Angulo,2000).

Devido à necessidade de busca por alternativas sustentáveis para deposição final de resíduos de construção e demolição, essa pesquisa tem como objetivo geral utilizar resíduos gerados por perdas físicas em canteiros de obras para substituição parcial e total do agregado graúdo dos concretos convencionais e analisar sua eficiência para fins estruturais. Isso se justifica na necessidade de alternativas eficientes para a reduzir a produção de RCD.

A reutilização de RCD na fabricação dos concretos convencionais poderá trazer um manejo sustentável nas construçães, visto que sua utilização possa gerar redução na exploração de recursos naturais, diminuição no volume de resíduo depositado no meio ambiente e redução na emissão de $\mathrm{CO} 2$, gerada pelas operações de transporte desse material até a destinação final. Logo, analisamos que a reciclagem desses rejeitos pode ser um elo sustentável na cadeia produtiva da construção civil e reuso de materiais.

\section{Referencial Teórico}

\subsection{Concretos Convencionais}

Os concretos convencionais atualmente são compostos por aglomerante, agregado graúdo, agregado miúdo e água, e para casos específicos são adicionados aditivos. Para Azeredo (1997), concreto é uma mistura de cimento, água e materiais inertes (geralmente areia, pedregulho, pedra britada ou argila expandida) que, empregado em estado plástico, endurece com o passar do tempo, devido à hidratação do cimento, isto é, sua combinação química com a água. A (NBR 12655, 2015) é a norma que rege o preparo, controle e recebimento do concreto e é aplicável ao cimento Portland para estruturas moldadas na obra, estruturas pré-moldadas e componentes estruturais pré-fabricados para edificações e estruturas de engenharia. 
Segundo Bauer (2019), no Brasil 85\% dos agregados britados são provenientes de granito, 10\% de rocha calcária e 5\% de basaltos. A Figura 1 mostra o agregado miúdo natural, cujo grãos passam pela peneira de 4,8 $\mathrm{mm}$ e ficam retidos na peneira de $0,075 \mathrm{~mm}$, e são classificados em areia fina, areia média e areia grossa. A figura 2 mostra o agregado graúdo natural, nesse caso a brita, cujo grãos ficam retidos na peneira de $4,8 \mathrm{~mm}$.

Figura 1. Agregado miúdo natural.

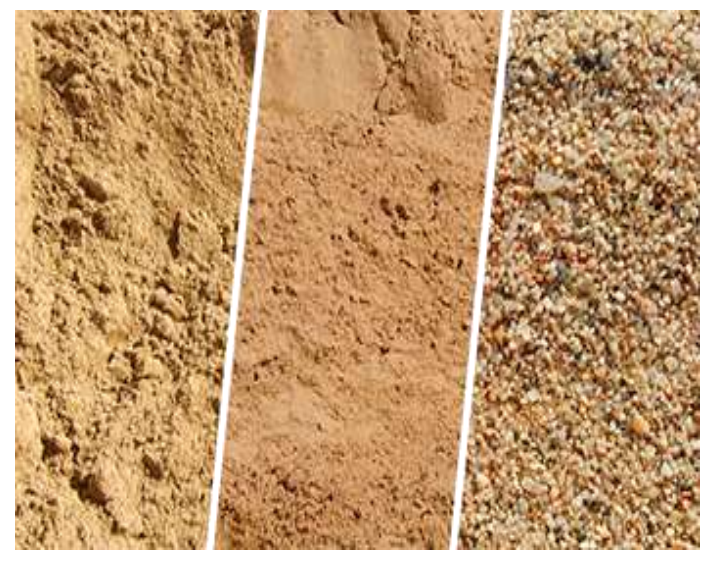

Fonte: Material de Construção (2016).
Figura 2. Agregado graúdo natural.

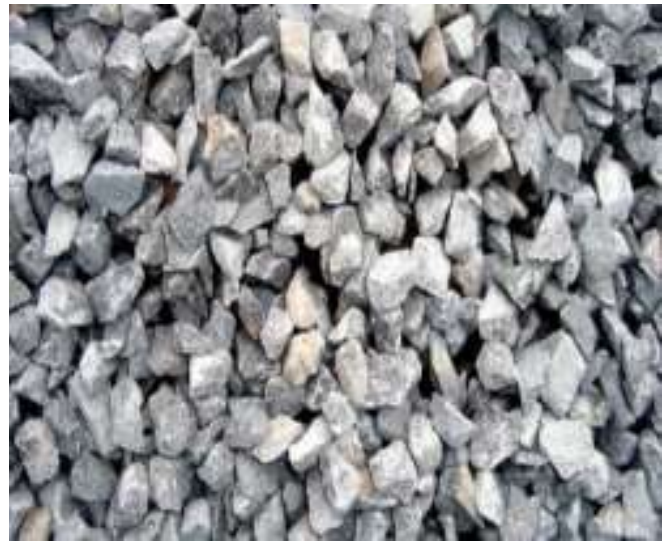

Fonte: Autores (2020).

Segundo Pinheiro e Crivelaro (2016), os agregados graúdos naturais (seixos de rios) não possuem ângulos e são geralmente arredondados, o que acarreta um aumento de fluidez da pasta por conta de menor atrito entre as partículas do agregado.

\subsection{Propriedades do Concreto}

O concreto é um material que tem por finalidade resistir aos esforços de compressão e proteger o aço, onde possui propriedades em seu estado fresco e endurecido. No estado fresco é analisado sua trabalhabilidade e no estado endurecido suas principais propriedades mecânicas são: resistência à compressão, resistência à tração e módulo de elasticidade.

A relação água/cimento é a proporção entre a água e o cimento presente no concreto, onde sua relação em massa pode variar entre 0,45 à 0,65 , onde esse valor pode determinar a resistência e durabilidade do concreto, Segundo (NBR 12655,2015). Sabe-se que além do fator relação água/cimento de um concreto, é de suma importância a proporção cimento e agregados para o concreto no estado fresco, ou seja, a pasta no estado fluido tanto para a trabalhabilidade quanto para a resistência mecânica final do concreto no estado endurecido. O conjunto pasta e espaços cheios de ar é modernamente chamado de matriz, sendo que os valores da resistência e de outras propriedades do concreto endurecido são determinados pela composição da matriz, particularmente pelo teor de cimento, afirma Sobral (2000). Como os agregados comumente são materiais resistentes, a matriz de argamassa é o material mais susceptível à porosidade, influenciando assim na resistência final do concreto.

\subsection{Resíduos de Construção e Demolição}

A resolução $\mathrm{n}^{\mathrm{o}} 307$ do Conselho Nacional do Meio Ambiente (CONAMA) estabelece diretrizes, critérios e procedimentos para a gestão dos resíduos da construção civil. Visto que o setor da construção civil tem uma grande demanda de volume de geração de resíduos, logo o objetivo dessa resolução é minimizar os impactos causados pela geração desses resíduos. 
Define-se que resíduos de construção são os provenientes de construções, reformas, reparos e demolições de obras de construção civil, e os resultantes da preparação e da escavação de terrenos, tais como tijolos, blocos cerâmicos, concreto em geral, solos, rochas, metais, resinas, colas, tintas, madeiras e compensados, forros, argamassas, gesso, telhas, pavimento asfálticos, vidros, plásticos, tubulações, fiação elétrica, etc., comumente chamados de entulhos de obras, caliça ou metralha (CONAMA, 2002).

\subsection{Concreto de Agregados Recicláveis}

São concretos produzidos com agregados provenientes de resíduos de construção e demolição, substituindo parcialmente ou totalmente os agregados naturais. Segundo a (NBR 15116, 2004), define como agregado reciclado todo material granular proveniente do beneficiamento de resíduos de construção ou demolição de obras civis, que apresentam características técnicas para a aplicação em obras de edificação e infraestrutura. Essa norma classifica os agregados em agregados de resíduos de concreto (ARC) que são rejeitos provenientes de concreto e agregados de resíduos mistos (ARM) que são rejeitos contendo mistura de outros materiais além do concreto.

\section{Metodologia}

Esse trabalho trata-se de uma pesquisa experimental, quantitativa, onde foi utilizado como suporte metodológico para a definição dos traços o método ABCP (Associação Brasileira de Cimento Portland).

Durante a pesquisa foram selecionadas três obras residenciais de pequeno porte em um bairro, na cidade de Sobral, Ceará, localizado na região norte. Essas obras foram identificadas como obra 1, obra 2 e obra 3, para assim manter discrição das construtoras e seus responsáveis técnicos. Foram coletadas amostras de entulhos produzidos em canteiros de obra para estudar sua reutilização, realizando substituição como agregado graúdo no traço moldado no laboratório em percentuais de substituição $0 \%, 50 \%$ e 100\%. Assim, o projeto experimental consta com 3 traços, para cada traço foram moldados 5 corpos de provas, que foram rompidos na idade de 7 e 28 dias.

\subsection{Materiais utilizados}

O aglomerante utilizado foi o Cimento Portland, CP II E-32 cimento com secagem rápida composto por escórias, da marca Votorantim, pois é o cimento comumente vendido e utilizado no mercado da região. O agregado natural graúdo utilizado na pesquisa foi a brita 01, proveniente da pedreira Minermac, localizada na cidade de Sobral, Ceará, Brasil. O agregado natural miúdo utilizado na pesquisa foi areia média proveniente das margens do rio Acaraú, na região norte do Ceará, Brasil. A água utilizada na produção das misturas de concreto foi água proveniente do Sistema de Abastecimento de Água e Esgoto (SAAE), da cidade de Sobral, Ceará, Brasil. O agregado reciclado de resíduo de construção e demolição utilizado foi extraído nas obras escolhidas. Aproximadamente $40 \mathrm{~kg}$ de material original foi separado pelo autor e posteriormente feito o processo de britagem manual.

\subsection{Preparação dos materiais}

Inicialmente foi feita uma coleta com amostra de entulhos produzidos nas obras, diretamente nas pilhas de rejeitos depositados ao lado da construção. Utilizou-se uma pá comum, recolheu-se as amostras dos resíduos depositando-as dentro de um balde e transferido para o laboratório da instituição de ensino. A Figura 3 mostra os entulhos da obra 1. 
Figura 3. Resíduos de construção da Obra 1.

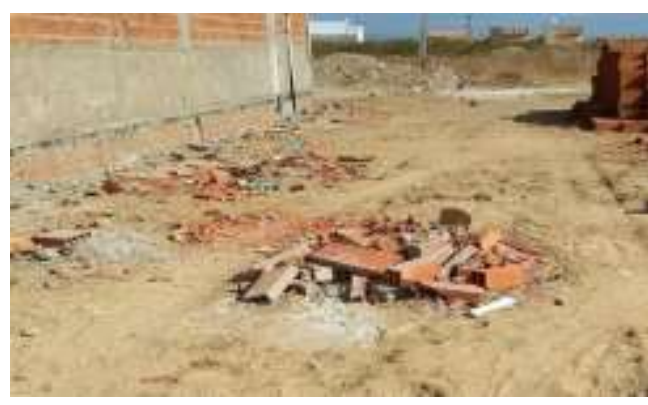

Fonte: Autores (2020).

Posteriormente, as amostras do material reciclado foram submetidas aos procedimentos de britagem, manualmente triturado com uma marreta para a diminuição da granulometria do entulho, homogeneizado e quarteado, seguindo a (NBR 6457, 2016) “Amostra de solo - Preparação para ensaios de compactação e ensaios de caracterização.” A Figura 4 mostra os resíduos triturados e colocado em estufa para secagem prévia do material.

Figura 4. Preparação amostra de resíduos.

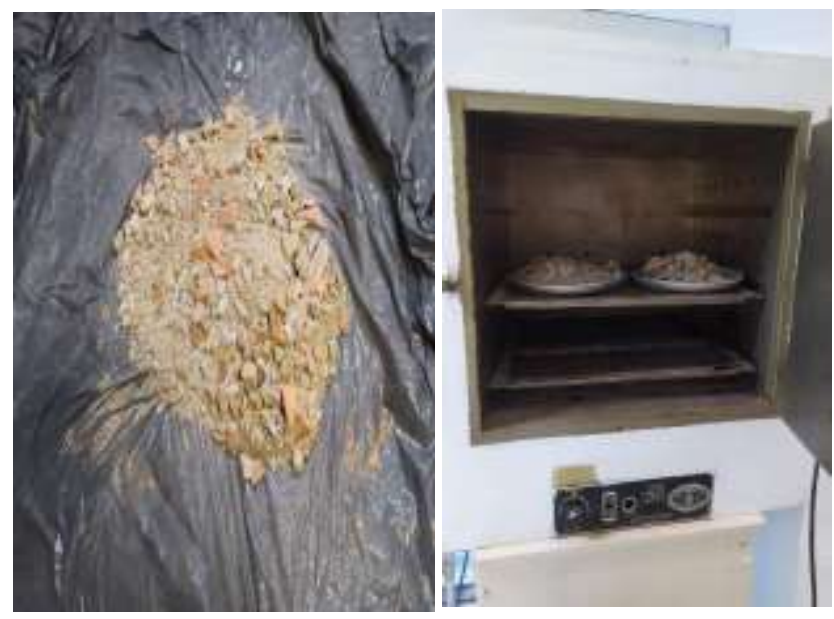

Fonte: Autores (2020).

Com o material já triturado, foi pesado em uma amostra de 2,0 kg e, posteriormente, passou por um processo de peneiramento, utilizando peneiras com malhas pré-determinadas conforme a (NBR NM 248, 2003) "Agregados Determinação da composição granulométrica". A granulometria dos agregados deve ser feita através do peneiramento, onde a massa de grãos retidas na faixa de $9,5 \mathrm{~mm}$ à $19 \mathrm{~mm}$ corresponde a graduação "brita 1 " e entre 9,5 mm à 4,8mm a graduação "brita 0", expressando assim o diâmetro máximo do agregado, que é a porcentagem retida acumulada no valor $5 \%$ ou exatamente menor, em milímetros. Figura 5 mostra a pesagem do material reciclado e sua separação nas peneiras de malhas $9,5 \mathrm{~mm}$ à $4,8 \mathrm{~mm}$. 
Figura 5. Ensaio de caracterização dos resíduos.
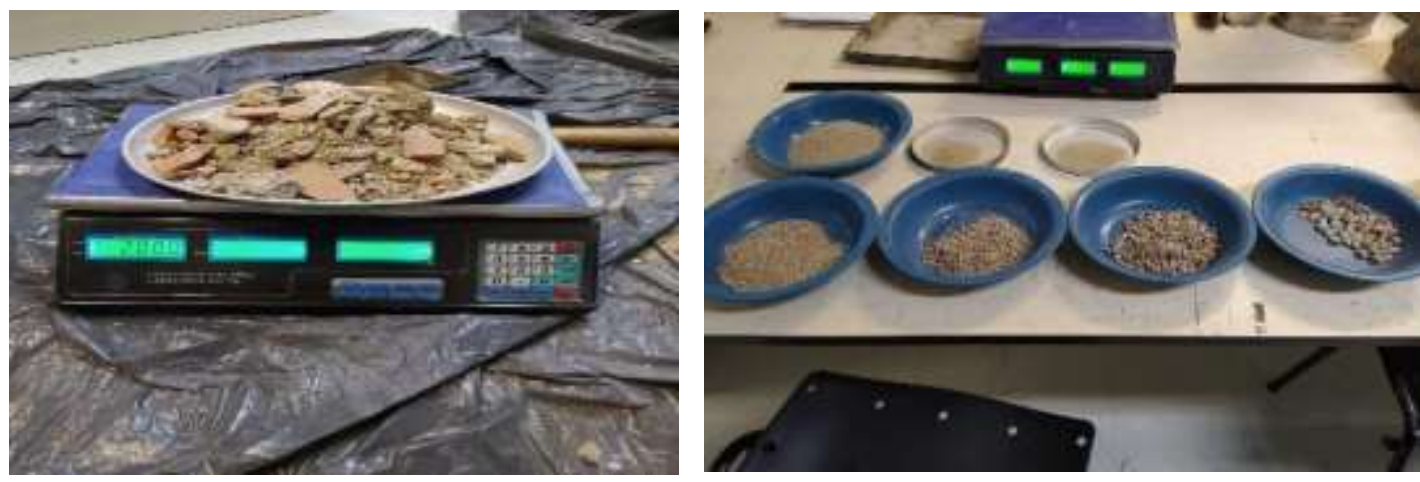

Fonte: Autores (2020).

\subsection{Dosagem dos traços}

O método utilizado para o cálculo da dosagem foi o da ABCP (Associação Brasileira de Cimento Portland). Para determinar o traço do concreto referência esta pesquisa adotou como parâmetro uma resistência a compressão axial com fck de $20 \mathrm{MPa}$ aos 28 dias, que é a resistência mínima conforme a (NBR 6118, 2014), e replicou o mesmo traço para o concreto RCD-50 que é o concreto com teor de substituição de 50\% do agregado natural pelo agregado reciclado e concreto RCD-100 que é o concreto com teor de substituição de $100 \%$ do agregado natural. Seguindo a recomendação desse método, foram realizados ensaios de caracterização dos agregados naturais para em seguida proceder com o cálculo do traço unitário de referência. Após a homogeneização da mistura na betoneira, foi retirada uma parte do concreto para moldagem dos corpos de prova. Por se tratar de uma dosagem experimental, o traço inicial pode ser alterado conforme resultado dos ensaios de consistência, no qual avaliam a sua trabalhabilidade pelo ensaio de Abatimento do tronco de cone (Slump Test). O Quadro 1 mostra os valores e caracterização do material natural utilizado.

Quadro 1. Caracterização do material natural.

\begin{tabular}{|l|c|c|c|c|c|c|c|}
\hline Material & $\begin{array}{c}\text { M.E. } \\
\left(\mathrm{Kg} / \mathrm{m}^{3}\right)\end{array}$ & $\begin{array}{c}\text { M.U. } \\
\left(\mathrm{Kg} / \mathrm{m}^{3}\right)\end{array}$ & M.F & $\begin{array}{c}\text { D. Máx. } \\
(\mathrm{mm})\end{array}$ & T.U. \% & C.F. & $\mathrm{Cl}$ \\
\hline Ag. Miúdo & 2570,7 & 1529,57 & 3,26 & 4,8 & - & - & 1,1 \\
\hline Ag. Graúdo & 2800 & 1370 & - & 19 & - & 1 & - \\
\hline Cimento & 3100 & 1400 & - & - & - & - & - \\
\hline
\end{tabular}

Fonte: Autores (2020).

Utilizando os valores de cálculo do traço unitário do consumo de material para o concreto referência conforme o Quadro 2, partiu-se para a produção da mistura na betoneira, em seguida foi feito o ensaio pelo abatimento de tronco do cone, conhecido como slump test, para a determinação da consistência do concreto, moldado em 3 camadas iguais e adensadas com 25 golpes cada camada. Após o ensaio, foi estabelecido que o concreto obteve uma consistência fluida de $150 \mathrm{~mm}$, segundo a (NBR NM 67, 1998), portanto, houve a necessidade de recalcular o valor e reajustar o fator a/c de 0,52 para 0,45 e a consistência resultante foi de $10 \mathrm{~mm}$ sendo classificada como seca. Foi recalculado novamente o valor a/c, ficando estabelecido em 0,50 obtendo assim uma consistência medianamente plástica de $30 \mathrm{~mm}$. O quadro 3 representa a quantidade em massa dos componentes do concreto referência. 
Quadro 2. Relação a/c e consistência do concreto.

\begin{tabular}{|c|c|}
\hline Abatimento $\mathbf{~ m m}$ & Fator a/c corrigido \\
\hline 150 & 0,52 \\
\hline 10 & 0,45 \\
\hline 30 & 0,50 \\
\hline
\end{tabular}

Fonte: Autores (2020).

Quadro 3. Traço em massa unitária.

\begin{tabular}{|c|c|c|c|}
\hline \multicolumn{4}{|c|}{ Representação do traço em massa unitária kg } \\
\hline $\mathbf{C}$ & $\mathbf{A m}$ & $\mathbf{A g}$ & $\mathbf{a} / \mathbf{c}$ \\
\hline 1 & 1,43 & 2,22 & 0,50 \\
\hline
\end{tabular}

Fonte: Autores (2020).

Feito o terceiro traço-base para o concreto referência e realizado o ensaio de abatimento de tronco do cone, obteve-se uma consistência desejada, moldou-se corpos de prova para ensaios de compressão axial do concreto no estado endurecido de acordo com a (NBR 5738, 2015), Concreto - Procedimento para moldagem e cura de corpos-de-prova. Após 24 horas, foram desmoldados e colocados submersos em água para a cura até o dia de rompimento, 7 e 28 dias.

\subsection{Dosagem concreto reciclado}

Utilizando o mesmo método do concreto referência com o mesmo traço, confeccionou-se os 2 tipos de concreto, o concreto RCD-50 e RCD-100, substituindo o agregado graúdo por agregados de resíduos de construção e demolição parcialmente em $50 \%$ e totalmente $100 \%$, respectivamente. Foram feitos os mesmos procedimentos de quantidade de consumo de material, mistura na betoneira e ensaio do concreto referência no estado fresco pelo abatimento de tronco no cone.

Primeiro concreto confeccionado foi o concreto RCD-100, no slump test, utilizando a mesma relação a/c do concreto referência, seu abatimento no cone foi de aproximadamente $0 \mathrm{~mm}$, ou seja, um concreto de consistência seca, baixa trabalhabilidade, portanto optou-se por aumentar o fator a/c de 0,50 para 0,6 , onde seu abatimento no cone ficou em $10 \mathrm{~mm}$. E assim também foi feito para o concreto RCD-50. O Quadro 4 representado em massa mostra os valores utilizados para a confecção do concreto RCD-100 e RCD-50.

Quadro 4. Traço em massa unitária.

\begin{tabular}{|c|c|c|c|c|c|}
\hline \multicolumn{7}{|c|}{ Representação do traço em massa unitária kg } \\
\hline Traço & C & Am & Agn & Agr & a/c \\
\hline RCD-100 & 1 & 1,43 & - & 2,2 & 0,6 \\
\hline RCD-50 & 1 & 1,43 & 1,1 & 1,1 & 0,6 \\
\hline
\end{tabular}

Fonte: Autores (2020).

Após a confecção e o ensaio de consistência, foram feitos os mesmos processos de moldagem dos corpos de prova para ensaio de resistência mecânica do concreto no estado endurecido. 


\section{Resultados e Discussão}

Foram analisadas a trabalhabilidade do concreto reciclado no estado fresco, ou seja, sua consistência após a confecção deles: traço referência, traço RCD-50 e traço RCD-100. Os resultados obtidos foram feitos através do ensaio de abatimento de tronco de cone conhecido como slump test. Como o objetivo deste ensaio é analisar a trabalhabilidade, a relação a/c fixa não foi mantida. Os resultados obtidos do slump test realizados estão apresentados na tabela abaixo, para os três concretos confeccionados. O Quadro 5 mostra os resultados da trabalhabilidade do concreto referência, concreto RCD-50 e concreto RCD-100.

Quadro 5. Análise da trabalhabilidade.

\begin{tabular}{|l|l|l|}
\hline TRAÇO & a/c & Slump \\
\hline TR & 0,5 & $30 \mathrm{~mm}$ \\
\hline TRCD-50 & 0,6 & $10 \mathrm{~mm}$ \\
\hline TRCD-100 & 0,6 & $10 \mathrm{~mm}$ \\
\hline
\end{tabular}

Fonte: Autores (2020).

O Quadro 6 mostra os resultados obtidos do ensaio de resistência à compressão, bem como um comparativo entre as resistências dos traços ensaiados, com suas respectivas relações a/c.

Quadro 6. Resultado da resistência de compressão axial.

\begin{tabular}{|l|l|l|l|}
\cline { 3 - 4 } \multicolumn{2}{l|}{} & \multicolumn{2}{|l|}{ Resistência a compressão (MPa) } \\
\hline Traço & $\mathbf{a} / \mathbf{c}$ & $\mathbf{7}$ dias & $\mathbf{2 8}$ dias \\
\hline TR & 0,5 & 22,96 & 28,37 \\
\hline TRCD-50 & 0,6 & 19,07 & 28,36 \\
\hline TRCD-100 & 0,6 & 19,11 & 23,99 \\
\hline
\end{tabular}

Fonte: Autores (2020).

Na sequência são apresentados os gráficos que mostram o comparativo de resistência à compressão axial aos 7 dias e aos 28 dias, para os três concretos analisados na Figura 6 e o que mostra o comparativo entre a tensão de ruptura com relação a idade na Figura 7. 
Research, Society and Development, v. 10, n. 5, e46010515246, 2021

(CC BY 4.0) | ISSN 2525-3409 | DOI: http://dx.doi.org/10.33448/rsd-v10i5.15246

Figura 6. Resistência à compressão.

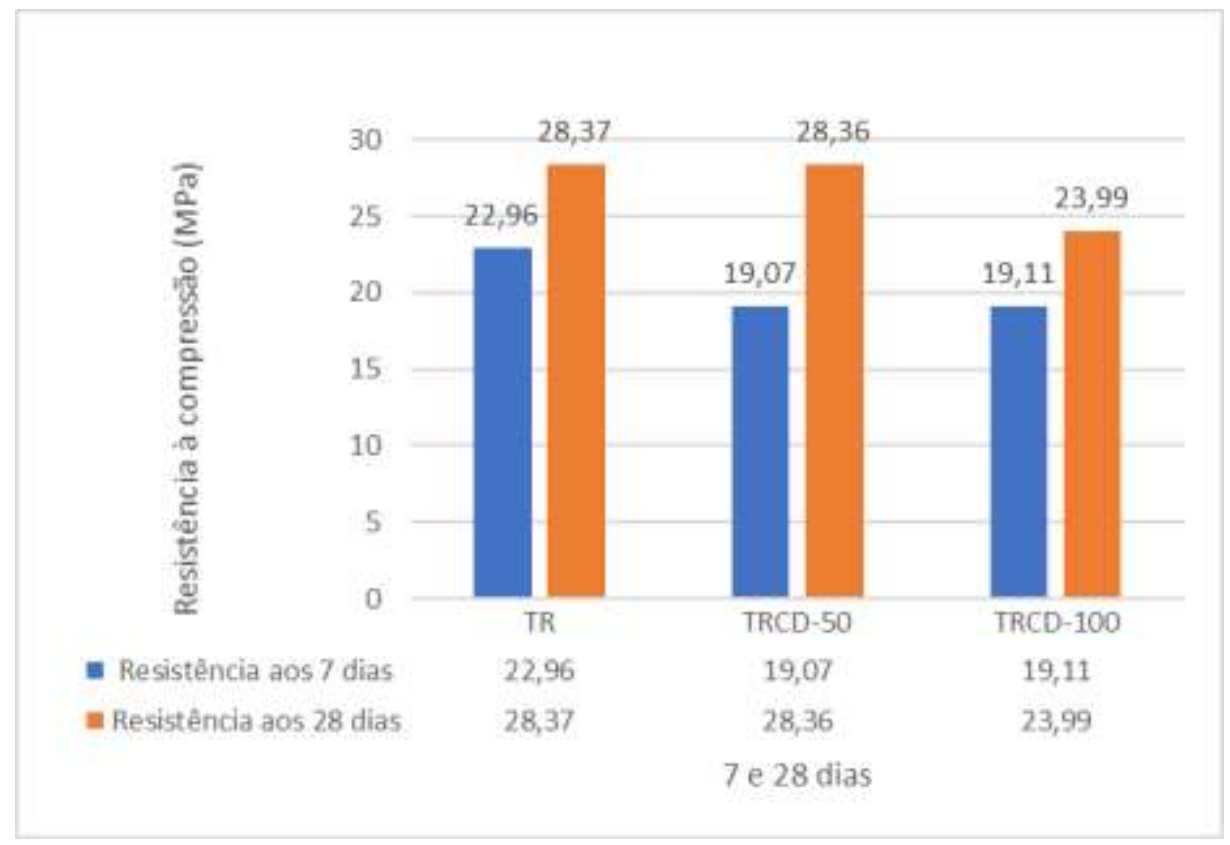

Fonte: Autores (2020).

Figura 7. Tensão de ruptura nas idades de 7 e 28 dias.

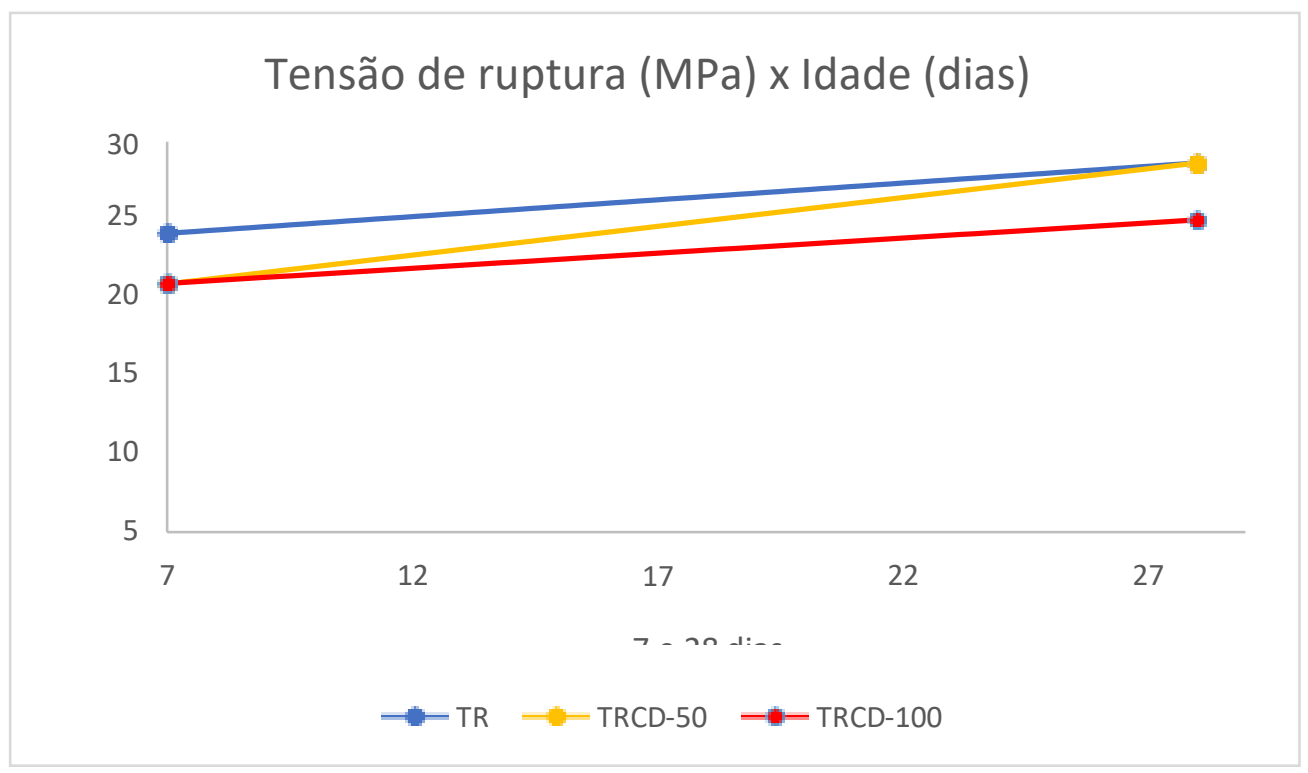

Fonte: Autores (2020).

Diante dos quadros e das figuras, analisando os valores obtidos de resistência à compressão axial, observa-se que todos os traços obtiveram os valores mínimos de $20 \mathrm{Mpa}$ aos 28 dias do processo de cura, conforme a Associação Brasileira de Cimento Portland (ABCP, 2016).

Analisando os resultados individualmente, observa-se na Figura 8 que na idade de 7 dias o TR apresentou uma resistência de 22,96 Mpa, atingindo rapidamente a resistência mínima, o TRCD-50 atingiu uma resistência de 19,07 Mpa, valor bem próximo do mínimo exigido e o TRCD-100 com resistência de 19,11 Mpa, também valor bem próximo a resistência 
mínima exigida pela (NBR 6118, 2014). Aos 28 dias do processo de cura todos os traços obtiveram um aumento significativo na sua resistência final, atingindo 28,37 Mpa, 28,36 Mpa e 23,99 Mp, para TR, TRCD-50 e TRCD-100, respectivamente.

Figura 8. Percentual de resistência aos 7 dias.

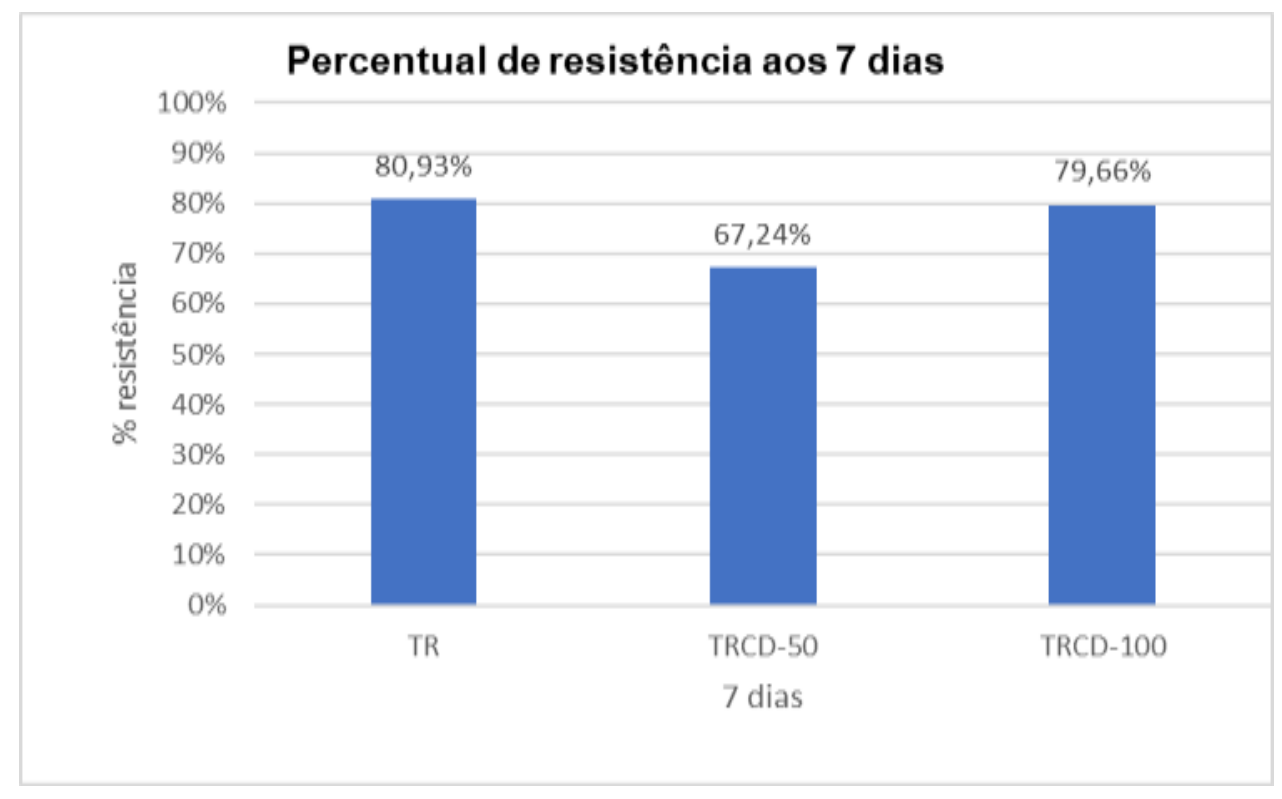

Fonte: Autores (2020).

Aos 7 dias percebe-se que o TR atingiu 80,93\% do valor da sua resistência final aos 28 dias, o TRCD-50 atingindo $67,24 \%$ e o TRCD-100 atingindo 79,66\%, valor bem próximo com o TR.

\section{Conclusão}

Este trabalho buscou analisar a viabilidade de utilizar esses resíduos como substituição parcial e total do agregado graúdo convencional nos teores de 50\% e 100\%. Os valores dos resultados da resistência à compressão axial aos 28 dias do TRCD-50 foi de 28,36 Mpa valor bem aproximado com o TR que aos 28 dias atingiu 28,37 Mpa e o TRCD- 100 foi de 23,99 $\mathrm{Mpa}$, ou seja, ambos os concretos atingiram valores superior ao valor mínimo para concreto estrutural definido pela (NBR $6118,2014)$ que é de $20 \mathrm{Mpa}$. Em relação a sua trabalhabilidade, houve a necessidade de aumento na relação a/c para ambos os concretos reciclados, visto que o agregado graúdo reciclado é um material poroso, requerendo assim um pouco mais de umidade no seu cálculo de dosagem.

Portanto pode-se concluir que os concretos RCD-50 e RCD-100 apresentaram valores satisfatórios para seu uso na construção civil, desde que seja feito todo controle tecnológico para sua produção e utilização. Com base nos resultados obtidos, o RCD-50 foi o que apresentou melhor resistência à compressão axial, sendo o mais propício para utilização com fins estruturais.

Sugestão para novos trabalhos:

- $\quad$ Analisar a resistência de concreto RCD com uso de aditivos químicos.

- $\quad$ Analisar a resistência substituindo o agregado miúdo convencional por agregado miúdo reciclado.

- $\quad$ Analisar a resistência do concreto RCD utilizando outros tipos de cimento na composição. 
Research, Society and Development, v. 10, n. 5, e46010515246, 2021

(CC BY 4.0) | ISSN 2525-3409 | DOI: http://dx.doi.org/10.33448/rsd-v10i5.15246

\section{Referências}

Ângulo, S.C. (2000). Variabilidade de agregados graúdos de resíduos de construção e demolição reciclados. São Paulo. Dissertação - Escola Politécnica da Universidade de São Paulo. <https://www.teses.usp.br/teses/disponiveis/3/3146/tde-05102005-112833/publico/variabilidade_sergio_angulo.pdf >.

Associação Brasileira de Cimento Portland. (2016). Guia básico de utilização do cimento Portland. 2016. <http://solucoesparacidades.com.br/wpcontent/uploads/2012/11/28-Guia-basico- de-utilizacao-do-cimento-portland.pdf >

Associação Brasileira de Normas Técnicas. ABNT NBR 12655. (2015). Concreto de cimento Portland - Preparo, controle, recebimento e aceitação Procedimento.

Associação Brasileira de Normas Técnicas. ABNT NBR 15116. (2004). Agregados reciclados de resíduos sólidos da construção civil - Utilização em pavimentação e preparo de concreto sem função estrutural.

Associação Brasileira de Normas Técnicas. ABNT NBR 6457. (2016). Amostra de solo - Preparação para ensaios de compactação e ensaios de caracterização.

Associação Brasileira de Normas Técnicas. NBR NM 248. (2003). Agregados - Determinação da composição granulométrica.

Associação Brasileira De Normas Técnica NBR 6118. (2014). Projetos de estruturas de concreto - Procedimento.

Associação Brasileira De Normas Técnica NBR NM 67. (1998). Ensaio de Abatimento do concreto (Slump Teste).

Associação Brasileira De Normas Técnica ABNT NBR 5738:2015 Versão corrigida: 2016. (2015). Concreto - Procedimento para moldagem e cura de corpos-de-provas.

Azeredo, H. A. (1997). O edifício até sua cobertura. Blucher.

Bauer, L. A. (2019). Materiais de construção. 1. LTC.

Conselho Nacional do Meio Ambiente (2002). Resolução CONAMA $n^{o}$ 307, de 5 de julho de 2002. < http://www2.mma.gov.br/port/com ama/legiabre.cfm?codlegi $=307$.

Crivelaro, M. \& Pinheiro, A. C. F. (2014). Materiais de construção. Ed. Érica.

Pinto, T. P. (1999). Metodologia para a gestão diferenciada de resíduos sólidos da construção urbana. São Paulo. Dissertação - Escola Politécnica da Universidade de São Paulo. < http://www.casoi.com.br/hjr/pdfs/GestResiduosSolidos.pdf >

Sobra, H. S. Propriedades do concreto fresco. 32 p. (6a ed.), https://edisciplinas.usp.br/pluginfile.php/3089801/mod_resource/content/0/ET15.pdf > 